\title{
Electrocardiogram Sequence
}

National Cancer Institute

\section{Source}

National Cancer Institute. Electrocardiogram Sequence. NCI Thesaurus. Code C83266.

An identifier that describes the relative position of electrocardiogram data within a series. 